\title{
Financial transfers from adult children and depressive symptoms among mid-aged and elderly residents in China - evidence from the China health and retirement longitudinal study
}

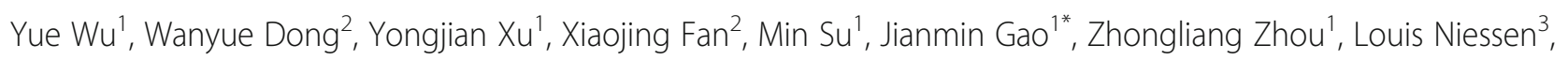
Yiyang Wang ${ }^{4}$ and Xiao Wang $^{4}$

\begin{abstract}
Background: Although the awareness of mental health problems in late life is rising, the association between financial transfers to the older generations from children and mental health at older ages in China has received little attention. This study examines the association between financial transfers from children and depressive symptoms among the mid-aged and elderly residents (from 45 years of age and older) in China.

Methods: We used the data from the China Health and Retirement Longitudinal Study (CHARLS, 2013) $(n=10,935)$ This included data on financial transfers from all non-co-resident children to their parents, and the individual scores on depressive symptoms as measured by the 10-item Center for Epidemiologic Studies-Depression Scale (CESD-10). A two-level - individual and community levels - mixed linear model was deployed to explore their association.

Results: Financial transfers from children to parents was the major component of inter-generational financial transfers in Chinese families. A higher financial support from non-co-resident children was signivicantly and positively related to fewer depressive symptoms (coef. $=-0.195, P$-value $<0.001)$ among both the mid-aged and elderly parents.

Conclusions: Financial transfers from non-co-resident children are associated with depressive symptoms among mid-aged and elderly residents in the China situation. Taxation and other policy measures should encourage and facilitate these type of financial transfers and prevent a decrease of support from children to parents.
\end{abstract}

Keywords: Depressive symptoms, Mid-aged and elderly residents, Multilevel model, CHARLS, China, Intergenerational transfer

\section{Background}

Depression, one of the most common mental disorders, affects approximately $7 \%$ of the world's elders [1]. Almost $30 \%$ of males and $43 \%$ of females among the mid-aged and elderly residents in China reportedly suffered from depressive symptoms [2], as measured by 10-item Center for Epidemiologic Studies-Depression

\footnotetext{
* Correspondence: gaojm@xjtu.edu.cn

${ }^{1}$ School of Public Policy and Administration, Xi'an Jiaotong University, Xi'an,

People's Republic of China

Full list of author information is available at the end of the article
}

Scale (CESD-10), a widely used tool for studying mental health or depression

Inter-generational transfer also is named as inter-genera tional exchange [3] or inter-generational support [4], which may flow upwards from offspring to their (grand) parents or flow downwards from the elderly to their offspring. The transfers include financial transfers, instrumental transfers, emotional transfers and other kinds of support between family members [5-7].Inter-generational transfers have previously been found contributing to psychological well-being of elders [8]. 
It is well-known that family support plays an extremely important role in residents' late life in Chinese traditional culture [9]. However, little research has explored the relationship between inter-generational transfers and mental health $[3,10]$. A finding in Anhui Province of China showed that, emigration enhanced the amount of financial transfers from non-co-resident children, and the transfer had a positive effect on psychological outcomes among parents living alone [11]. Meanwhile, a finding among female elders in rural China showed that receipt of financial transfers from their children was negatively associated with subjective health [4]. So far there is no research based on nationally representative data, the research results were inconsistent and the extent of transfers and depressive symptoms were seldom measured $[12,13]$. Moreover, family networks and community relationships which likely are significantly associated with mental health [14-16], have hitherto seldom studied.

Therefore, using a nationally representative data, our study aims to examine whether financial transfers - both money support and in-kind support - from non-co-resident children are associated with the parents' depressive symptoms in the China situation. The extent to which the financial transfers were received and number of depressive symptoms were measured, and the community-level effect was involved in the analysis as well. This study may broaden our understanding of the relationship between financial transfer and mental health among elderly Chinese parents, and inform policy making.

\section{Methods}

\section{Data and sampling}

Data were from the second wave of China Health and Retirement Longitudinal Study(CHARLS). The baseline of CHARLS was designed based on the Health and Retirement Study (HRS), the English Longitudinal Study of Ageing (ELSA), the Survey of Health, Ageing and Retirement in Europe (SHARE), and similar longitudinal aging surveys in other countries. The second wave of CHARLS used in this study was held in 2013, which covered 445 villages $\backslash$ communities in 150 counties\districts within 28 provinces, where a multistage stratified sampling strategy and Probability-Proportional-to-Size Sampling(PPS) were adopted to sample participants aged 45 years old and above [17]. In the case of household sampling, all the buildings in each Primary sampling unit (PSU) were photographed and GPS positioned, and the households in each building were listed. Among them, collective residences such as military, schools, dormitories and nursing homes are excluded from the sample set. Accordingly, participants $(n=18,605)$ in CHARLS (2013) are all non-institutional.
CHARLS includes questions involving various aspects of mid-aged and elderly residents' lives, including transfers among family members and depressive symptoms measured by 10-item Center for Epidemiologic StudiesDepression Scale (CESD-10) [18]. Our sample framework include non-institutional respondents with complete data on the financial transfers ( $>0 \mathrm{RMB}$ ) from their own children, depressive symptoms and other major possibly related co-variables.

\section{Measurement of depressive symptoms}

A Chinese version 10-item short form of the Center for Epidemiologic Studies-Depression Scale (CESD-10) was used to assess respondents' depressive symptoms in CHARLS, and an additional file shows this in more detail [see Additional file 1]. The scale has been shown to have good reliability and validity (Cronbach's $\alpha=.81$ ) [19].

In our study, scores of 10 items were calculated as the value of dependent variable $[2,20]$. The 10 items consisted of eight negatively oriented and two positively oriented questions. The negatively oriented ones included statements like "I was bothered by things that don't usually bother me" and the positive ones are "I felt hopeful about the future" and "I was happy". Each item was assessed by a four-point scale, scored as follows: $0=$ Rarely or none of the time ( $<1$ day), $1=$ Some or a little of the time (1-2 days), $2=$ Occasionally or a moderate amount of the time (3-4 days), and $3=$ Most or all of the time (5-7 days). The two positively oriented items were scored inversely. The CESD-10 score ranged from 0 to 30 ; the higher the scores, the more depressive symptoms a participant has.

\section{Measurement of inter-generational financial transfers}

Financial and in-kind support from non-co-resident children in the past 1 year were used to assess financial transfers. The sum value of all children's supports was calculated, and the logarithm of the sum was taken as independent variable value as in a related study [21]. The economic supports including total money support and total in-kind support, calculated in Chinese Renminbi Yuan ( 1 yuan $=0.1582$ US dollars). Total money supports include living expenses such as water, electricity, telephone rates and loans, as well as other - regular and irregular - costs. Total in-kind supports include food, clothes, and other regular and irregular material support.

\section{Measurement of control variables}

Other factors that may affect inter-generational transfers and depressive symptoms were included in the analysis as well. The control variables were grouped into four categories: other transfers, demographic characteristics, 
socio-economic characteristics, and current health status and social activity variables.

The specific variables of other transfers included: support for care of grandchildren, indicating whether grandchild care was provided, coding as 0 (not taking care of grandchildren) and 1 (taking care of grandchildren) [22]. Frequency of contact with children was measured by how often did they contact with each child, coding as 0 (seldom, more than once a year), 1 (sometimes, more than once a week and less than once a year), and 2(often, less than once a week). The means of the contact included phone call, text message, mail, or email. Living arrangement indicated whether one respondent lived with any child, coding as 0 (no) and 1 (yes).

Demographic characteristics included: gender $(0=$ male; $1=$ female $)$, marital status $(0=$ other $; 1=$ living with a spouse), and age (were grouped into 4 groups based on the quartiles: $0=45-56$ years old $; 1=57-62$ years old $; 2=63-69$ years old $; 3=70$ years and older). Socioeconomic characteristics included: Education (continuous variable), ranging from 0 (illiterate) to 10 (Master's degree). Income, measured by net household expenditure per capita, where net household expenditure was calculated as total household consumption expenditure [23], and the logarithm of net household expenditure per capita was deployed to assess the income level. Community development level, assessed by the summed number of amenities/associations. Geographical divisions of China, ranging from 0 to $6(0=$ Northwest (worst economic development); $1=$ Southwest; $2=$ Northeast; $3=$ East; $4=$ South; $5=$ Central; $6=$ North). Urban and rural areas were coded as 0 (rural) and 1(urban).

Health and social factors included: Activities of daily living (ADL), for which we asked the respondents whether have any difficulties with activities of daily living (dressing/bathing/eating/getting (in/out of) bed/using the toilet) $(0=$ no; $1=$ yes $)$. The sum of diagnosed chronic disease ranged from 0 to 14 (e.g. hypertension, diabetes or high blood sugar). The respondents were also asked whether they participated in any social activities (e.g. interacted with friends, played Ma-jong, or went to community club) $(0=$ no; $1=$ yes $)$, and whether they were at work $(0=$ no; $1=$ yes $)$.

\section{Statistical analysis}

As the CHARLS data were collected based on multistage stratified sampling, and community was significantly associated with mental health, a 2-level mixed linear model [24] was conducted to assess the relationship between receipt of financial transfers and depressive symptoms. The first level is individual level $(n=10,935)$, and the second level is community level $(n=445)$. STATA12.0 was used for the statistical analysis.

\section{Results}

\section{Characteristics of study population}

The proportion of elder adults receving financial support from their children is 61.5. Table 1 presents the included characteristics of the respondents who receving financial support from their children in the study. The sample size of this study was 10,935. The mean value of CESD-10 score and logarithm of inter-generational financial transfers were $7.3(\mathrm{SD}=6)$ and $7.5(\mathrm{SD}=1.3)$, respectively.

In terms of control variables, the average age was $(62.7 \pm 9.13)$ years old. Females accounted for almost half of the sample (46.8\%). Among the respondents, less than half of them lived with their child (43.3\%), and more than four fifths of them lived with spouse (86.0\%). Respondents from rural areas (66.3\%) were almost twice of whom from urban areas (33.7\%). Very few of the respondents had difficulty with ADL (7.2\%), and almost two-thirds of the respondents remained at work (65\%).

\section{Inter-generational transfers and depressive symptoms}

Results of the mixed-effects multilevel regression analysis are presented in Table 2. The results indicate that there was a significantly negative correlation between inter-generational financial transfers from children and depressive symptoms among the mid-aged and elderly residents in China $(P<0.001)$. The relationship was controlled by the effects of other variables such as other transfers with children, demographic factors, socioeconomic factors, and health and social factors.

Table 2 also indicates the associations between control variables and depressive symptom. We found the risk factors of depressive symptoms including taking care of grandchildren, aged 62-69 years old, being females, having difficulty with ADL, being diagnosed with more chronic diseases, as well as protective factors including living with a child or spouse, aged 69 years old and over, living in better developed or urban areas, higher levels of education, income and community development, participating in social activities.

\section{Discussion}

This is the first study reporting the inverse association between extent of financial transfers and depressive symptoms among the mid-aged and elderly Chinese and is based on a large-scale, nationally representative survey (CHARLS) in China. It provides convincing evidence that a higher amount of financial support from non-co-resident children is positively related to less depressive symptoms among their older Chinese parents.

\section{Inter-generational financial transfers in China}

In Europe, inter-generational financial transfers are in the opposite direction i.e. mainly from parents to children [5, $8,25]$. Our study shows that economic resources between 
Table 1 Descriptive statistics of the study sample $(N=10,935)$

\begin{tabular}{|c|c|c|c|}
\hline \multicolumn{2}{|l|}{ Variables } & \multirow{2}{*}{$\begin{array}{l}\text { Mean (\%) } \\
7.3\end{array}$} & \multirow{2}{*}{$\frac{S D}{6}$} \\
\hline Dependent variable & $\begin{array}{l}\text { Depressive symptoms } \\
\text { (cesd-10a score) (0-30) }\end{array}$ & & \\
\hline Independent variable & $\begin{array}{l}\text { Inter-generational financial } \\
\text { transfers (log of transfers) }\end{array}$ & 7.5 & 1.3 \\
\hline \multirow[t]{10}{*}{ Other transfers } & $\begin{array}{l}\text { Whether take care of } \\
\text { grandchildren }\end{array}$ & & \\
\hline & No (ref.) & $58.1 \%$ & \\
\hline & Yes & $41.9 \%$ & \\
\hline & Contact with children & & \\
\hline & Seldom(ref.) & $37.4 \%$ & \\
\hline & Sometimes & $34.5 \%$ & \\
\hline & Often & $28.1 \%$ & \\
\hline & Living with any child & & \\
\hline & No(ref.) & $56.7 \%$ & \\
\hline & Yes & $43.3 \%$ & \\
\hline \multirow[t]{11}{*}{ Demographic factors: } & Age group & & \\
\hline & 45-56(ref.) & $23.7 \%$ & \\
\hline & $56-62$ & $24.9 \%$ & \\
\hline & $62-69$ & $25.4 \%$ & \\
\hline & $69-$ & $26.0 \%$ & \\
\hline & Gender & & \\
\hline & Male (ref.) & $46.8 \%$ & \\
\hline & Female & $53.2 \%$ & \\
\hline & Marital status & & \\
\hline & Other (ref.) & $14.0 \%$ & \\
\hline & Living with spouse & $86.0 \%$ & \\
\hline \multirow[t]{14}{*}{ Socioeconomic factors: } & Education level $(1-10)^{b}$ & 3.1 & 1.9 \\
\hline & Income level & 8.6 & 1 \\
\hline & Amenities/associations $(0-14)^{c}$ & 3.1 & 3.4 \\
\hline & Areas of china & & \\
\hline & Northwest (ref.) & $6.1 \%$ & \\
\hline & Southwest & $18.9 \%$ & \\
\hline & Northeast & $7.1 \%$ & \\
\hline & East & $23.9 \%$ & \\
\hline & South & $8.4 \%$ & \\
\hline & Central & $22.4 \%$ & \\
\hline & North & $13.2 \%$ & \\
\hline & Rural-urban & & \\
\hline & Rural (ref.) & $66.3 \%$ & \\
\hline & Urban & $33.7 \%$ & \\
\hline \multirow[t]{4}{*}{ Health and social factors: } & Any difficulty with $A D L^{d}$ & & \\
\hline & No (ref.) & $92.8 \%$ & \\
\hline & Yes & $7.2 \%$ & \\
\hline & Chronic disease $(0-10)^{\mathrm{e}}$ & 0.4 & 0.8 \\
\hline
\end{tabular}


Table 1 Descriptive statistics of the study sample $(N=10,935)$ (Continued)

\begin{tabular}{lll}
\hline Variables & Mean (\%) \\
\hline & Whether participated in any & \\
social activities & $39.6 \%$ \\
& No (ref.) & $60.4 \%$ \\
& Yes & \\
Whether still on work & $35.0 \%$ \\
No (ref.) & $65.0 \%$ \\
Yes &
\end{tabular}

$S D=$ standard deviation

${ }^{a}$ CEDS-10: Center for Epidemiologic Studies Depression Scale (Range 0-30, Mean = 7.3, SD =6.0)

${ }^{\mathrm{b}}$ Education level: including 10 levels, $1=$ No formal education (illiterate) $; 2=$ Did not finish primary school but capable of reading and/or writing; $3=$ home school; 4

= Elementary school; $5=$ Middle school; 6 = High school; $7=$ Vocational school; $8=$ Two-/Three-Year College/Associate degree; $9=$ Four-Year College/Bachelor

degree; $10=$ Master degree (Range1-10, mean $=3.1, \mathrm{SD}=1.9$ )

c Amenities/associations (0-14): Summed number of amenities/associations, was used to assess community building level, which was significantly associated with the mental health. (Rang 0-14, Mean $=3.1, \mathrm{SD}=3.4$ )

${ }^{d}$ ADL: activities of daily living (dressing, walking, bathing, eating, getting in/out of bed, toileting, and experiencing incontinence)

e Chronic disease: summed number of diagnosed chronic disease (hypertension, Dyslipidemia, diabetes or high blood sugar, Cancer or malignant tumor, Chronic lung diseases, Liver disease, Heart attack, Stroke, Kidney disease, Stomach or other digestive disease, Stomach or other digestive disease, Stomach or other digestive disease, Arthritis or rheumatism, Asthma) (range0-14, Mean $=0.4, \mathrm{SD}=0.8$ )

parents and adult children flow mainly from children to parents $(n=10,935)$, while it finds a very small number of transfers from parents to children. Additionally, compared to the amount of elders' received financial support, the amount given to their adult children was relatively small in China $[4,10,21,26]$. That is in line with the transfer direction in some Asian countries, such as in Korea and Philippines [26, 27]. We did not include financial transfer from parents to children in our analyses, as the number of transations and the amount per transaction are very low.

Factors connected with the specific configuration of welfare regimes are relevant to inter-generational transfers [5]. The particular pattern and direction of inter-generational transfer in China could be interpreted by the following factors connected with the specific configuration of welfare regimes, like those in relation to 'family policy' [28, 29]. In China, children hold obligations to support their parents [30], and the adult children should support their elderly parents financially and ensure their basic living needs [31]. The accelerated emigration as well as inadequate pension and health insurances for the elderly, especially in China's rural areas, made it particularly urgent to oblige non-co-resident children to support their parents financially [32]. Additionally, Chinese traditional culture of "filial piety is the foundation of all virtues" may play an important role in cross-generational transfer between children and parents [33].

\section{Inter-generational financial transfers and depressive symptoms}

Higher levels of economic resources and better health are show to be positively associated in other studies. [34, 35]. In relation to inter-generational financial transfers, Jewish Israelis and Coreans showed that the effect of financial support from children was not significant assocated to reduce depression $[3,27]$. This is in contrast to our study findings that show a increased financial support from non-co-resident children positively related to less depressive symptoms among older parents. This is similar to findings in Hong Kong and Taiwan [10].

Findings for other studies may explain the positive association that higher amount of receipt of financial transfer from non-co-resident children and fewer depressive symptoms among mid-aged and elderly parents in China. When there is internal emigration by working-age adults from rural to urban and from western to eastern China, fewer old parents live with children, we found that less than half $(41.9 \%)$ of the older parents lived with one of their children. Thus, for adult children, financial transfers may be a kind way to compensate the effects of living apart from their parents [11]. Additionally, where there is a lack of inadequate pension and health insurance for the elders, especially in rural areas and less developed regions (such as western China), more elderly parents have to depend on financial supports from their adult children [32]. However, financial transfers from adult children is not just about the money aspect, it is part of the overall connection between generations. It is important that elderly parents embedded in inter-generational relationship actually enjoy them [27] as this is part of the Chinese traditional cultural of filial piety to take good care of old parents. Higher financial transfers from adult children may reflect a greater personal filial bonds and this may explain the lower risk of depressive symptoms [36]. Emotional support has a large influence on elders' mental health [37] which may agree with our observation that a higher amount of financial transfers from adult children relates to to fewer depressive symptoms among the elders. Therefore, financial transfers and emotional support to old parents should be encouraged to prevent detoriation of the 
Table 2 Mixed-effects ML regression results

\begin{tabular}{|c|c|c|c|c|c|}
\hline \multirow[t]{2}{*}{ Variables } & & \multirow[t]{2}{*}{ B } & \multirow[t]{2}{*}{ SE } & \multicolumn{2}{|l|}{$95 \% \mathrm{Cl}$} \\
\hline & & & & Low & High \\
\hline Independent variable & Inter-generational financial transfers (log of transfers) & $-0.226^{c}$ & 0.044 & -0.314 & -0.140 \\
\hline \multirow[t]{10}{*}{ Other transfers } & Whether take care of grandchildren & & & & \\
\hline & No (ref.) & & & & \\
\hline & Yes & $0.286^{\mathrm{a}}$ & 0.117 & 0.057 & .516 \\
\hline & Frequency of contact with children & & & & \\
\hline & Seldom (ref.) & & & & \\
\hline & Sometimes & -0.071 & 0.132 & -0.329 & 0.187 \\
\hline & Often & $-0.293^{a}$ & 0.142 & -0.572 & -0.014 \\
\hline & Living with any child & & & & \\
\hline & No (ref.) & & & & \\
\hline & Yes & $-0.363^{b}$ & 0.116 & -0.590 & -0.134 \\
\hline \multirow[t]{11}{*}{ Demographic factors: } & Age group (years old) & & & & \\
\hline & $45-56$ (ref.) & & & & \\
\hline & $56-62$ & 0.269 & 0.162 & -0.048 & 0.586 \\
\hline & $62-69$ & $0.448^{b}$ & 0.167 & 0.122 & 0.775 \\
\hline & $69-$ & $-.761^{c}$ & 0.189 & -1.131 & -0.391 \\
\hline & Gender & & & & \\
\hline & Male (ref.) & & & & \\
\hline & Female & $1.547^{c}$ & 0.120 & 1.311 & 1.781 \\
\hline & Marital status & & & & \\
\hline & Other (ref.) & & & & \\
\hline & Living with spouse & $-0.649^{c}$ & 0.170 & -0.983 & -0.315 \\
\hline \multirow[t]{14}{*}{ Socioeconomic factors: } & Education level (1-10) & $-0.087^{\mathrm{a}}$ & 0.035 & -0.1561 & -0.018 \\
\hline & Income level & $-0.170^{b}$ & 0.059 & -0.285 & -0.056 \\
\hline & Amenities/associations (0-14) & $-0.072^{b}$ & 0.028 & -0.126 & -0.018 \\
\hline & Areas of china & & & & \\
\hline & Northwest (ref.) & & & & \\
\hline & Southwest & -0.411 & 0.357 & -1.110 & 0.288 \\
\hline & Northeast & $-2.414^{c}$ & 0.422 & -3.241 & -1.586 \\
\hline & East & $-1.994^{c}$ & 0.348 & -2.675 & -1.313 \\
\hline & South & $-1.267^{b}$ & 0.403 & -2.058 & -0.478 \\
\hline & Central & $-1.307^{c}$ & 0.350 & -1.994 & -0.621 \\
\hline & North & $-1.420^{c}$ & 0.380 & -2.165 & -0.675 \\
\hline & Rural-urban & & & & \\
\hline & Rural (ref.) & & & & \\
\hline & Urban & $-0.546^{b}$ & 0.202 & -0.941 & -0.151 \\
\hline \multirow[t]{7}{*}{ Health and social factors: } & Any difficulty with $A D L$ & & & & \\
\hline & No (ref.) & & & & \\
\hline & Yes & $1.595^{c}$ & 0.220 & 1.164 & 2.026 \\
\hline & Chronic disease (0-10) & $0.259^{c}$ & 0.065 & 0.131 & 0.387 \\
\hline & Whether participated in any social activities & & & & \\
\hline & No (ref.) & & & & \\
\hline & Yes & $-1.695^{\mathrm{C}}$ & 0.115 & -1.920 & -1.470 \\
\hline
\end{tabular}


Table 2 Mixed-effects ML regression results (Continued)

\begin{tabular}{|c|c|c|c|c|c|}
\hline \multirow[t]{2}{*}{ Variables } & & \multirow[t]{2}{*}{ B } & \multirow[t]{2}{*}{ SE } & \multicolumn{2}{|l|}{$95 \% \mathrm{Cl}$} \\
\hline & & & & Low & High \\
\hline & \multicolumn{5}{|l|}{ Whether still on work } \\
\hline & \multicolumn{5}{|l|}{ No (ref.) } \\
\hline & Yes & -0.065 & 0.136 & -0.332 & 0.203 \\
\hline & _cons & $13.203^{c}$ & 0.896 & 11.855 & 14.551 \\
\hline
\end{tabular}

$M L=$ Multi-level; $B=$ unstandardized coefficient; $S E=$ Standard error; $C l$ : Confidence interval

${ }^{\mathrm{a}} p<0.05,{ }^{\mathrm{b}} p<0.01,{ }^{\mathrm{c}} p<0.001$

mental health of older partnes, especially in case of non-co-resident children.

For more robust results, we controlled for demographic, socioeconomic, heath status and community-level variables of the mid-aged and elderly parents; rural-urban areas and seven geographic regions of China were all involved in the analysis. Consistent with the literatures [20, 23, 38], aging (aged 62-69 compare with aged 45-56 years old), being females, having poorer health status are risk factors of depressive symptoms; while living with a child or spouse, having better socioeconomic status and living in well developed areas are protective factors. Intergenerational relationships are maintained by reciprocity [22], and thus taking care of grandchildren might be a kind of life burden for old parents which is a risk factor of having depressive symptoms. Besides, among the aged 45-56, 5662, 62-69 years old groups, the percent of taking care of grandchildren were $44.75,54.91,47.68$ and $21.4 \%$. We thus suppose the aged 69 years old and over group compare with the groups with younger age might have less life burden such as taking care of grandchildren. As a result, the parents aged 69 years old and over may experience fewer depressive symptoms.

Several limitations need to be considered in the interpretion of our results. First, since this study was based on cross-sectional data, the causality between inter-generational financial transfers and depressive symptoms could not be determined. Second, in CHARLS CESD-10 questions and answers were based on self-report andthus reported bias may exist in this study. Third, because of too few financial transfers from parents to children, it's impossible to adjust for these in this study. To explore this problem, we adjusted for taking care of grandchildren, which is a main kind of transfer giving by parents in China, to limit this potential bias.

\section{Conclusions}

Our study revealed that higher amount of financial support from non-co-resident children was positively related to fewer depressive symptoms among the mid-aged and elderly parents in China. Potential policy interventions may need to be explored to promote these and to fill the gaps when financial transfer from adult children decrease.

\section{Additional file}

Additional file 1: CESD-10 questions and answers (DOCX $15 \mathrm{~kb}$ )

Abbreviations

ADL: Aactivities of daily living:; CESD-10: 10-item Center for Epidemiologic Studies-Depression Scale; CHARLS: China Health and Retirement

Longitudinal Study

\section{Acknowledgements}

The authors would like to thank the China Health and Retirement Longitudinal Study (CHARLS) team for providing data.

\section{Funding}

Not applicable as no specific funding for the research has been received.

\section{Availability of data and materials}

The datasets generated and analysed during the current study are available in the China Health and Retirement Longitudinal Study official website repository,http://charls.pku.edu.cn/zh-CN/page/data/2013-charls-wave2. Our algorithms and crude analysis results are available from the corresponding author on reasonable request.

\section{Authors' contributions}

YW, JG, ZZ, LN and YX developed and designed the study. JG, ZZ and LN provided constructive suggestions on data analysis. YW, WD, XF, MS, YYW and $X W$ were performed the data analysis.YW, WD and $Y X$ were responsible for drafting the manuscript. XF, MS, JG, ZZ, LN, YYW and XW revised this work critically for important intellectual content. All authors critically reviewed and approved the final manuscript.

\section{Ethics approval and consent to participate}

Ethical approval for data collection was obtained at Peking University and updated annually. Approval for this study was given by the medical ethics committee of Health Science Center of Xi'an Jiaotong University (approval number 2015-642). All respondents gave written informed consent prior to data collection.

\section{Consent for publication}

Not applicable.

\section{Competing interests}

The authors declare that they have no competing interests.

\section{Publisher's Note}

Springer Nature remains neutral with regard to jurisdictional claims in published maps and institutional affiliations.

\section{Author details}

${ }^{1}$ School of Public Policy and Administration, Xi'an Jiaotong University, Xi'an, People's Republic of China. ${ }^{2}$ School of Public Health, Center of Medical Science, Xi'an Jiaotong University, Xi'an, People's Republic of China. ${ }^{3}$ Liverpool School of Tropical Medicine, Pembroke Place, Liverpool, UK. ${ }^{4}$ International Business School Suzhou, Xi'an Jiaotong-Liverpool University, Suzhou, Jiangsu, People's Republic of China. 
Received: 20 March 2018 Accepted: 4 July 2018

Published online: 16 July 2018

\section{References}

1. WHO. Mental health and older adults. Available: http://www.who.int/ mediacentre/factsheets/fs381/en/. Accessed 15 Jan. 2018.

2. Lei $X Y$, Sun $X T$, Strauss J, Zhang P, Zhao YH. Depressive symptoms and SES among the mid-aged and elderly in China: evidence from the China health and retirement longitudinal study national baseline. Soc Sci Med. 2014;120:224-32.

3. Litwin $\mathrm{H}$. Intergenerational exchange and mental health in later-life-the case of older Jewish Israelis. Aging Ment Health. 2004;8(3):196-200.

4. Li SZ, Song L, Feldman MW. Intergenerational support and subjective health of older people in rural China: a gender-based longitudinal study. Australas J Ageing. 2009;28(2):81-6.

5. Albertini M, Kohli M, Vogel C. Intergenerational transfers of time and money in European families: common patterns - different regimes? J Eur Soc Policy. 2007;17(4):319-34

6. McGarry K, Schoeni RF. Transfer behavior in the health and retirement study - measurement and the redistribution of resources within the family. J Hum Resour. 1995;30:S184-226.

7. Silverstein M, Parrott TM, Bengtson VL. Factors that predispose middle-aged sons and daughters to provide social support to older parents. J Marriage Fam. 1995;57(2):465-75.

8. Fritzell J, Lennartsson C. Financial transfers between generations in Sweden. Ageing Soc. 2005;25:397-414.

9. Chappell NL, Kusch K. The gendered nature of filial piety-a study among Chinese Canadians. J Cross Cult Gerontol. 2007;22(1):29-45.

10. Chao SF. Assessing social support and depressive symptoms in older Chinese adults: a longitudinal perspective. Aging Ment Health. 2011; 15(6):765-74.

11. Silverstein M, Cong Z, Li SZ. Intergenerational transfers and living arrangements of older people in rural China: consequences for psychological well-being. J. Gerontol. B Psychol. Sci Soc Sci. 2006; 61(5):S256-66.

12. Roll A, Litwin $\mathrm{H}$. Intergenerational financial transfers and mental health: an analysis using SHARE-Israel data. Aging Ment Health. 2010;14(2):203-10.

13. Luo HQ, Wu K, Qian JH, Cao PY, Ren XH. Urban-rural differences in the role of family support in physical and mental health of elderly people in China. Sichuan Da Xue Xue Bao Yi Xue Ban. 2017:48(2):263-7.

14. Shen YY. Community building and mental health in mid-life and older life: evidence from China. Soc Sci Med. 2014;107:209-16.

15. Smith JP, Tian M, Zhao Y. Community effects on elderly health: evidence from CHARLS National Baseline. J Econ Ageing. 2013;(1):50-9.

16. Li LW, Liu JY, Zhang ZM, Xu HW. Late-life depression in rural China: do village infrastructure and availability of community resources matter? Int J Geriatric Psychiatry. 2015;30(7):729-36.

17. Zhao Y, Hu Y, Smith JP, Strauss J, Yang G. Cohort profile: the China health and retirement longitudinal study (CHARLS). Int J Epidemiol. 2014;43(1):61-8

18. Andresen EM, Malmgren JA, Carter WB, Patrick DL. Screening for depression in well older adults - evaluation of a short-form of the Ces-D. Am J Prev Med. 1994;10(2):77-84

19. Lewinsohn PM, Seeley JR, Roberts RE, Allen NB. Center for epidemiologic studies depression scale (CES-D) as a screening instrument for depression among community-residing older adults. Psychol Aging. 1997;12(2):277-87.

20. Li LW, Liu JY, Xu HW, Zhang ZM. Understanding rural-urban differences in depressive symptoms among older adults in China. J Aging Health. 2016; 28(2):341-62.

21. Liu XT, Lu B, Feng ZX. Intergenerational transfers and informal care for disabled elderly persons in China: evidence from CHARLS. Health Soc Care Comm. 2017;25(4):1364-74.

22. Cong Z, Silverstein M. Caring for grandchildren and intergenerational support in rural China: a gendered extended family perspective. Ageing Soc. 2012;32:425-50.

23. Xu Y, Yang J, Gao J, Zhou Z, Zhang T, Ren J, Li Y, Qian Y, Lai S, Chen G. Decomposing socioeconomic inequalities in depressive symptoms among the elderly in China. BMC Public Health. 2016;16(1):1214.

24. Goldstein H. Multilevel statistical models, 4th edition[J]. 2010.

25. Scodellaro C, Khlat M, Jusot F. Intergenerational financial transfers and health in a national sample from France. Soc Sci Med. 2012;75(7):1296-302.
26. Agree EM, Biddlecom AE, Chang M-C, Perez AE. Transfers from older parents to their adult children in Taiwan and the Philippines. J cross-cultural gerontology. 2002;17(4):269-94.

27. Lee HJ, Lyu J, Lee CM, Burr JA. Intergenerational financial exchange and the psychological well-being of older adults in the Republic of Korea. Aging Ment Health. 2014;18(1):30-9.

28. Kaufmann F-X, Kuijsten A, Schulze H-J, Strohmeier KP, editors. Family life and family policies in Europe: problems and issues in comparative perspective. Oxford: Oxford University Press; 2002.

29. Matzke M, Ostner I. Introduction: change and continuity in recent family policies. J Eur Soc Policy. 2010;20(5):387-98.

30. People's Republic of China (PRC), Marriage law of the People's Republic of China. Available: http://www.gov.cn/banshi/2005-05/25/content_847.htm. Accessed 15 Jan. 2018.

31. People's Republic of China (PRC). Law of the People's Republic of China on the protection of the rights and interests of the elderly. Available: http:// www.gov.cn/flfg/2012-12/28/content_2305570.htm. Accessed 15 Jan. 2018.

32. Wu X, Li L. The motives of intergenerational transfer to the elderly parents in China: consequences of high medical expenditure. Health Econ. 2014; 23(6):631-52.

33. Pan $Y Q$, Jones PS, Winslow BW. The relationship between mutuality, filial piety, and depression in family caregivers in China. J Transcult Nurs. 2017; 28(5):455-63.

34. Mackenbach JP, Martikainen P, Looman CW, Dalstra JA, Kunst AE, Lahelma E, Sw $g$. The shape of the relationship between income and self-assessed health: an international study. Int J Epidemiol. 2005;34(2):286-93.

35. Adams P, Hurd MD, McFadden D, Merrill A, Ribeiro T. Healthy, wealthy, and wise? Tests for direct causal paths between health and socioeconomic status. Nber Conf R. 2004:415-526.

36. Dong XQ, Li MT, Hua YX. The association between filial discrepancy and depressive symptoms: findings from a community-dwelling Chinese aging population. J Gerontol a-Biol. 2017;72:S63-8.

37. Chao SF. Assessing social support and depressive symptoms in older Chinese adults: a longitudinal perspective. Aging Ment Health. 2011; 15(6):765.

38. Yang B, Yu HM, Xing M, He RL, Liang RF, Zhou LY. The relationship between cognition and depressive symptoms, and factors modifying this association, in Alzheimer's disease: a multivariate multilevel model. Arch Gerontol Geriat. 2017;72:25-31.

\section{Ready to submit your research? Choose BMC and benefit from:}

- fast, convenient online submission

- thorough peer review by experienced researchers in your field

- rapid publication on acceptance

- support for research data, including large and complex data types

- gold Open Access which fosters wider collaboration and increased citations

- maximum visibility for your research: over $100 \mathrm{M}$ website views per year

At BMC, research is always in progress.

Learn more biomedcentral.com/submissions 